\title{
CHANNA PARDALIS, A NEW SPECIES OF SNAKEHEAD (TELEOSTEI: ChANNIDAE) FROM MEghALAYA, NORTHEASTERN INDIA
}

\section{J.D. Marcus Knight}

ISSN 0974-7907 (Online) ISSN 0974-7893 (Print)

Flat 'L', Sri Balaji Apartments, $7^{\text {th }}$ Main Road, Dhandeeswaram, Velachery, Chennai, Tamil Nadu 600042, India jdmarcusknight@yahoo.co.in

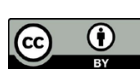

Abstract: Channa pardalis, a new species of snakehead, is described from Khasi Hills, Meghalaya, northeastern India. This species can be distinguished from its congeners by a unique colour pattern consisting of numerous large black spots on the post-orbital region of the head, opercle and body; a broad white and black margin to the dorsal, anal and caudal fins; $36-37$ dorsal fin rays; $24-25$ anal fin rays; $44-45$ pored scales on the body and two scales on the caudal fin base; $4 \frac{1}{2}$ scales above lateral line and $6 \frac{1}{2}$ scales below lateral line; 45 vertebrae and the palatine with two rows of teeth: outer row with numerous minute teeth and inner row with short, stout inward curved teeth.

Keywords: Channa melanostigma, Channa sterwartii, eastern Himalaya, northeastern India, taxonomy.

Snakeheads of the family Channidae are characterized by accessory air-breathing organs, which are modified expanded epibranchials situated in the suprabranchial cavity in the head (Liem 1980). These fish are distributed in tropical Africa, parts of the Middle East and Asia, and inhabit a wide variety of freshwater habitats ranging from hill streams to derelict swamps (Geetakumari \& Vishwanath 2011). Currently there are 35 valid species in the genus Channa, many of which are valued as food fish and a few that are popular in the aquarium trade. The Eastern Himalayan region harbors 10 endemic species of snakeheads (Britz 2013), some of which were recently discovered (Musikasinthorn 2000; Geetakumari \& Vishwanath 2011; Britz 2013).

Playfair (1867) described Ophiocephalus stewartii (currently assigned to Channa) from Cachar, Assam, characterized by "some larger teeth in the lower jaw and on the vomer and the palatine bone...most of the scales behind the roots of the pectorals have a round black spot in the centre...in young examples the pectorals have transverse darker cross bands...etc" (Fig. 1). For more than 150 years, $C$. stewartii was the only known Channa species with round black spots on the body until Britz (2008) described C. ornatipinnis and C. pulchra from Myanmar with spots on the body similar to $C$. stewartii. Subsequently, Geetakumari \& Vishwanath (2011) described C. melanostigma from Arunachal Pradesh, northeastern India, a species similar to $C$. stewartii. Recently, I had an opportunity to examine a colourful species of Channa from the Khasi Hills, Meghalaya, northeastern India, with large well-defined black spots on post-orbital region of the head, opercle and body. Detailed comparison with topotypic $C$. stewartii revealed that this was a species hitherto unknown to science, which is described herein as Channa pardalis sp. nov.

DOI: http://dx.doi.org/10.11609/jott.2168.8.3.8583-8589 | ZooBank: urn:Isid:zoobank.org:pub:F69CB8B6-233F-4C8D-86DF-CF02A1AEAD95

Editor: Anonymity requested.

Date of publication: 26 March 2016 (online \& print)

Manuscript details: Ms \# 2168 | Received 21 July 2015 | Final received 12 March 2016 | Finally accepted 17 March 2016

Citation: Knight, J.D.M. (2016). Channa pardalis, a new species of snakehead (Teleostei: Channidae) from Meghalaya, northeastern India. Journal of Threatened Taxa 8(3): 8583-8589; http://dx.doi.org/10.11609/jott.2168.8.3.8583-8589

Copyright: @ Knight 2016. Creative Commons Attribution 4.0 International License. JoTT allows unrestricted use of this article in any medium, reproduction and distribution by providing adequate credit to the authors and the source of publication.

Funding: None.

Conflict of Interest: The author declares no competing interests.

Acknowledgements: I gratefully acknowledge the support provided by the Director, Zoological Survey of India, Kolkata; K. Ilango (Officer-in-charge) and Jayasree Thilak (Scientist-D), of the Southern Regional Centre, Zoological Survey of India, Chennai. I thank Andrew Rao, Nikhil Sood, Beta Mahatvaraj, Pranay Kumar and Praveen Raj for helping me obtain the material used in this study. I am grateful to Ralf Britz for his valuable inputs, Unmesh Katwate for his help in depositing material at the Bombay Natural History Society, Pascal Antler and Paul Jones for constructive discussions. 


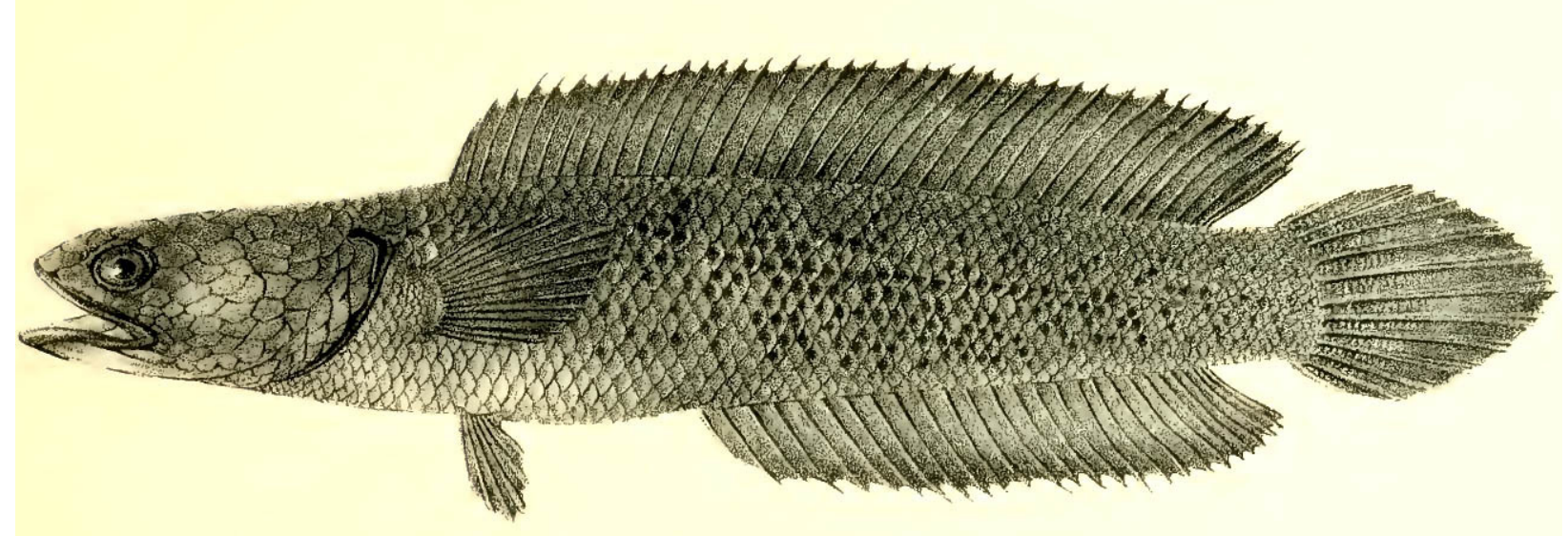

Figure 1. Original drawing of Ophiocephalus stewartii in Playfair (1867: PI. 3). Image flipped to face left.

\section{MATERIAL AND MethodS}

Collected specimens were fixed in $10 \%$ formalin and preserved in $70 \%$ alcohol. Specimens examined in this study are registered in the collections of the Bombay Natural History Society (BNHS), Mumbai, India; Southern Regional Centre, Zoological Survey of India, Chennai, India (ZSI/SRC). Additional material are in the collection of J.D. Marcus Knight (MKC), Chennai, India. Methods for taking counts and measurements follow Musikasinthorn (1998) and Britz (2008). Measurements were made with digital calipers to the nearest $0.1 \mathrm{~mm}$. Numbers in parenthesis after a count denotes the frequency of that count. Osteological preparations were made following the single-staining procedure of Taylor \& Van Dyke (1985) and osteological nomenclature follows Britz (2008). Vertebrae were counted from two cleared and stained specimens (MKC 429 and 437). Photographs were taken with Olympus SP570 UZ digital camera using super-macro mode. Data from Musikasinthorn (2000) and Britz (2008, 2013) were used for comparison. Original descriptions of Ophiocephalus aurantiacus, O. kelaartii, O. gachua var. basalis, Ophicephalus montanus and O. nigricans were also used for comparison.

\section{Channa pardalis sp. nov.} (Image 1, 2A)

urn:Isid:zoobank.org:act:394A6CAB-1802-48FF-AD89-5264F466474B

Holotype: BNHS FWF 181, $127.5 \mathrm{~mm} \mathrm{SL}$; streams in Nongstoin $\left(25.52^{\circ} \mathrm{N} \& 91.27^{\circ} \mathrm{E} ; \sim 1,400 \mathrm{~m}\right)$, West Khasi Hills, Meghalaya, India, coll. A. Rao, December 2012.

Paratypes: BNHS FWF 182, $141.1 \mathrm{~mm}$ SL; ZSI/SRC F 8954, 139.3mm SL, Collection information same as holotype.
Additional material: MKC 429, $102.1 \mathrm{~mm} \mathrm{SL;} \mathrm{MKC}$ $437,114.2 \mathrm{~mm} \mathrm{SL}$, both the specimens were cleared and stained for osteology. Collection information same as holotype.

Diagnosis: Channa pardalis sp. nov. is diagnosed from all other species of Channa in having a unique colour pattern consisting of numerous large black spots on the post-orbital region of the head, opercle and body; a broad white and black margin to the dorsal fin, anal fin and caudal fin; 36-37 dorsal fin rays; $24-25$ anal fin rays; 44-45 pored scales on the body and two scales on the caudal fin base; $4 \frac{1}{2}$ scales above lateral line and $61 / 2$ scales below lateral line; 45 vertebrae and the palatine with two rows of teeth: outer row with numerous minute teeth and inner row with short, stout inward curved teeth.

\section{Description}

See Table 1 for morphometric data and images 1 and 2A for general appearance. Body elongate, round in cross section anteriorly its width a little less than its depth; gradually becoming laterally compressed towards caudal peduncle. Dorsal profile of head gently curved anteriorly, ventral profile almost straight. Caudal peduncle deep, its depth greater than its length. Head large, dorso-ventrally flattened, about one-third standard length its widest portion between eye and opercle. Eyes small, located anteriorly on head, their diameter less than the snout length.

Mouth large, oblique, lips thick, angle of gape extending beyond the posterior margin of the eye. Lower jaw projecting slightly beyond upper jaw. Scales on cheeks in 4(1) - 5(4) rows. Both jaws with multiple rows of sharp, pointed teeth. Two rows of teeth on the lower jaw, an outer row of numerous minute slender pointed teeth 


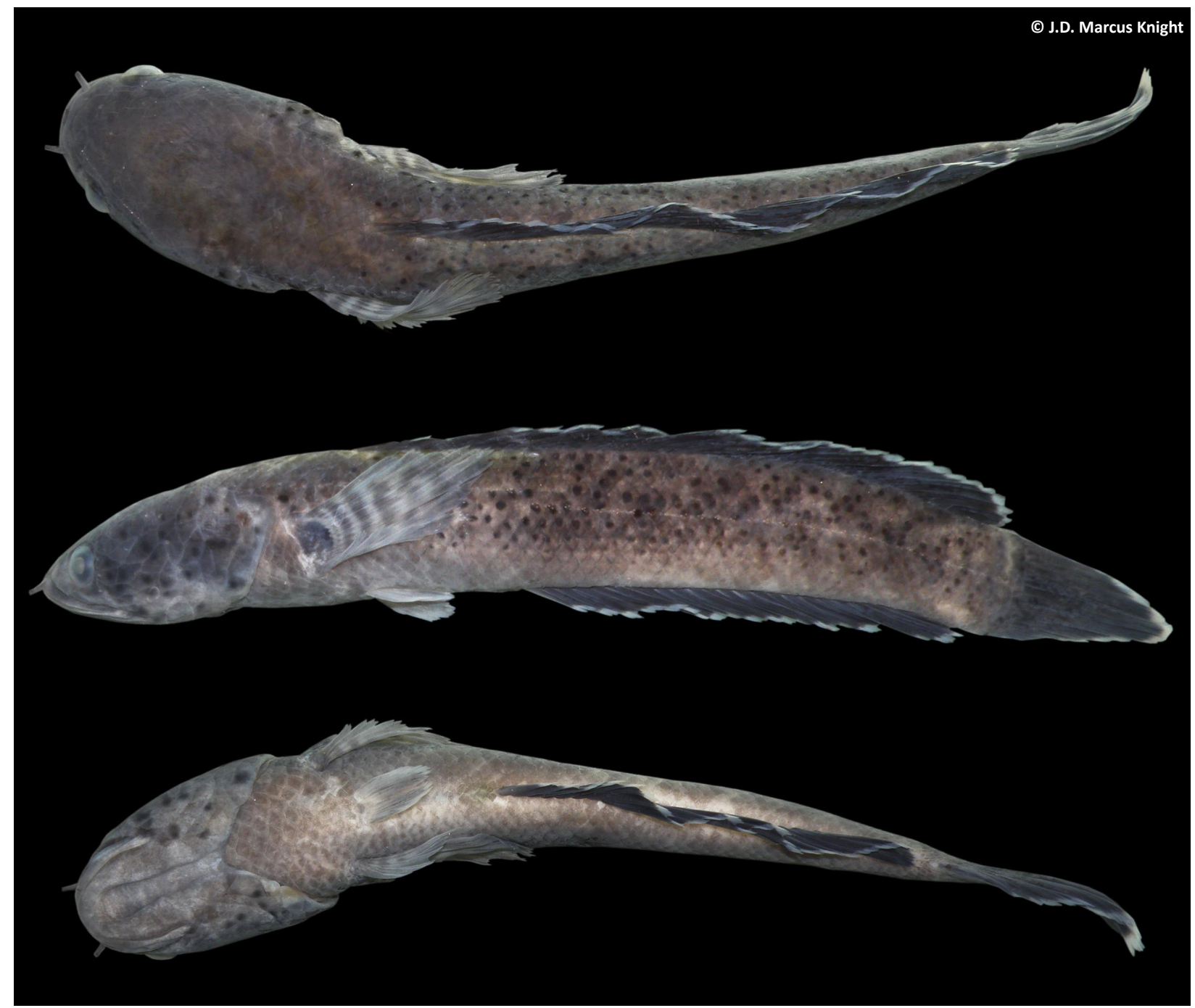

Image 1. Channa pardalis holotype, BNHS, FWF 181, 127.5mm SL.

and single inner row of large uniform sized teeth. Vomer with six small sharp, pointed teeth and four canine-like teeth. Two rows of teeth on the palatine, outer row with numerous minute teeth and inner row with short, stout inward curved teeth. Fifth ceratobranchial slender, with numerous long sharp inward pointing teeth (Image 3A).

Lateral line with 44(2)-45(3) pored scales on the body and two scales on the caudal fin base, extending from shoulder girdle in a horizontal line, dropping one scale row at scale $14(1)$ or $15(4)$, then continuing horizontally to caudal peduncle. $4 \frac{1}{2}$ scales above lateral line and $6 \frac{1}{2}$ scales below lateral line at anal-fin origin. Pre-dorsal scales $14(1)-15(4)$. Vertebrae 45 (40 abdominal +5 caudal). Dorsal-fin rays 36(1) $-37(4)$; anal-fin rays $24(4)-$ 25(1); pectoral fin rays 14; caudal-fin rays 13(6+7).

\section{Colouration}

In alcohol (Image 1), dorsum, sides of head and body uniformly dark grey gradually becoming lighter towards the throat and abdomen. Fifteen to twenty well defined black spots on the post-orbital region of the head, opercle and with numerous black spots along the flanks extending into the dorsal fin and caudal fin, which sometimes fade to become dark grey and on prolonged preservation become inconspicuous. Dorsal, anal and caudal fins dark grey with a broad white and black margin. Pectoral fin cream with three or four dark grey semi-circular bands. Pelvic fin grey with a white margin.

Live specimens (Image 2A) are bluish-grey in colour; top of the head and opercular region bright blue. 15-20 well defined black spots on the post-orbital region of the head and opercle. Body with bluish dorsum gradually becoming grey towards the abdomen, with numerous 
Table 1. Morphometric data of Channa pardalis sp. nov. $(n=5)$. Ranges include values of holotype.

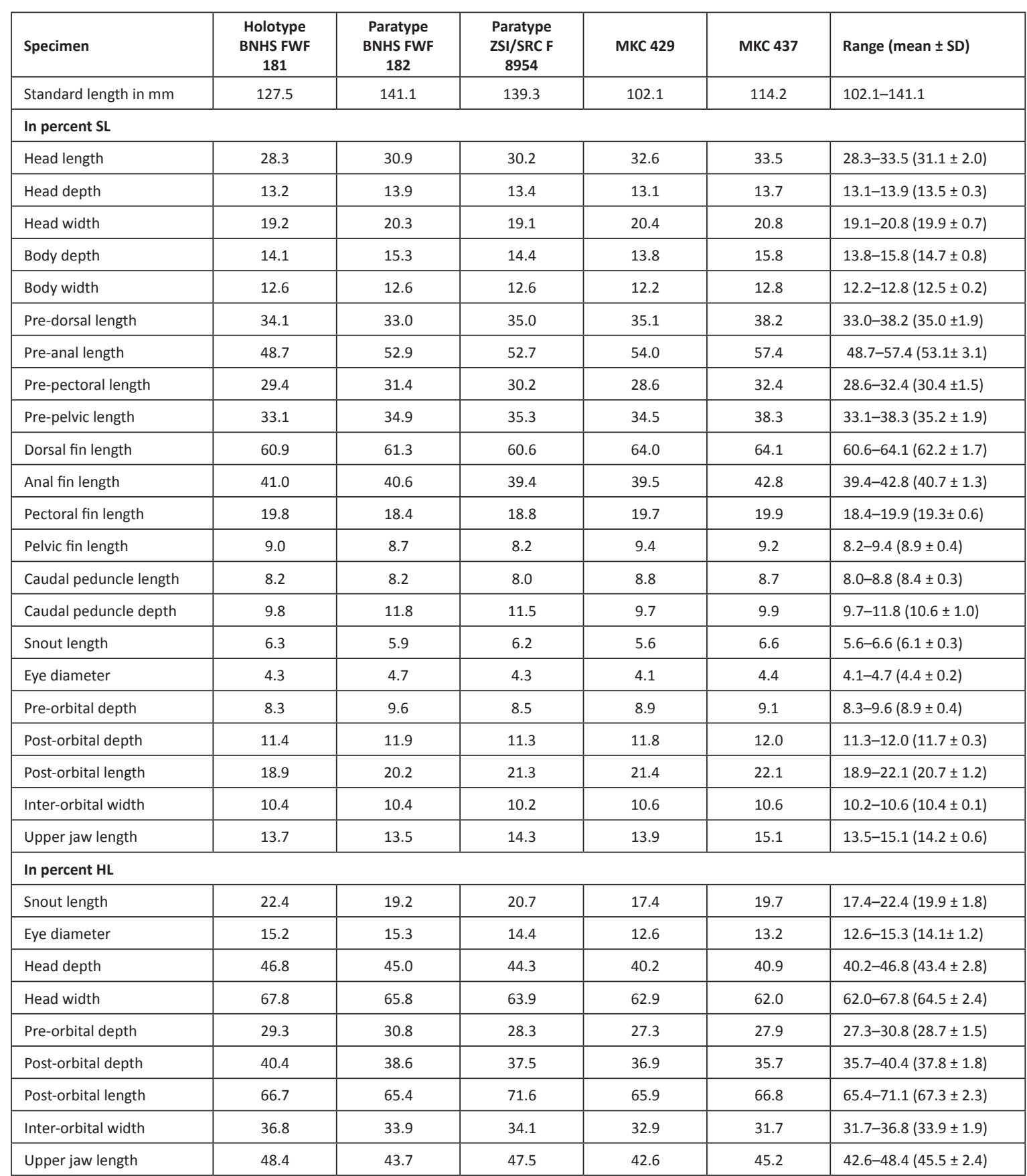

black spots along the flanks extending into the dorsal fin and caudal fin. Dorsal fin, anal fin and caudal fin bright blue with a broad white and black margin. Pectoral fin with bright blue spot at the base, and with three or four alternating pale orange and grey semi-circular bands which fade towards the distal part of the fin which is dark grey. Pelvic fin grey with a white margin. Sclera dark orange with two orange patches: one on the anterior margin of the orbit and the other below the orbit.

\section{Etymology}

The specific epithet 'pardalis' is a Latin adjective meaning 'Leopard' referring to the conspicuous spots the species has, similar to a leopard.

\section{Distribution}

Channa pardalis sp. nov. is currently known only from the Khasi Hills, Meghalaya, northeastern India. 


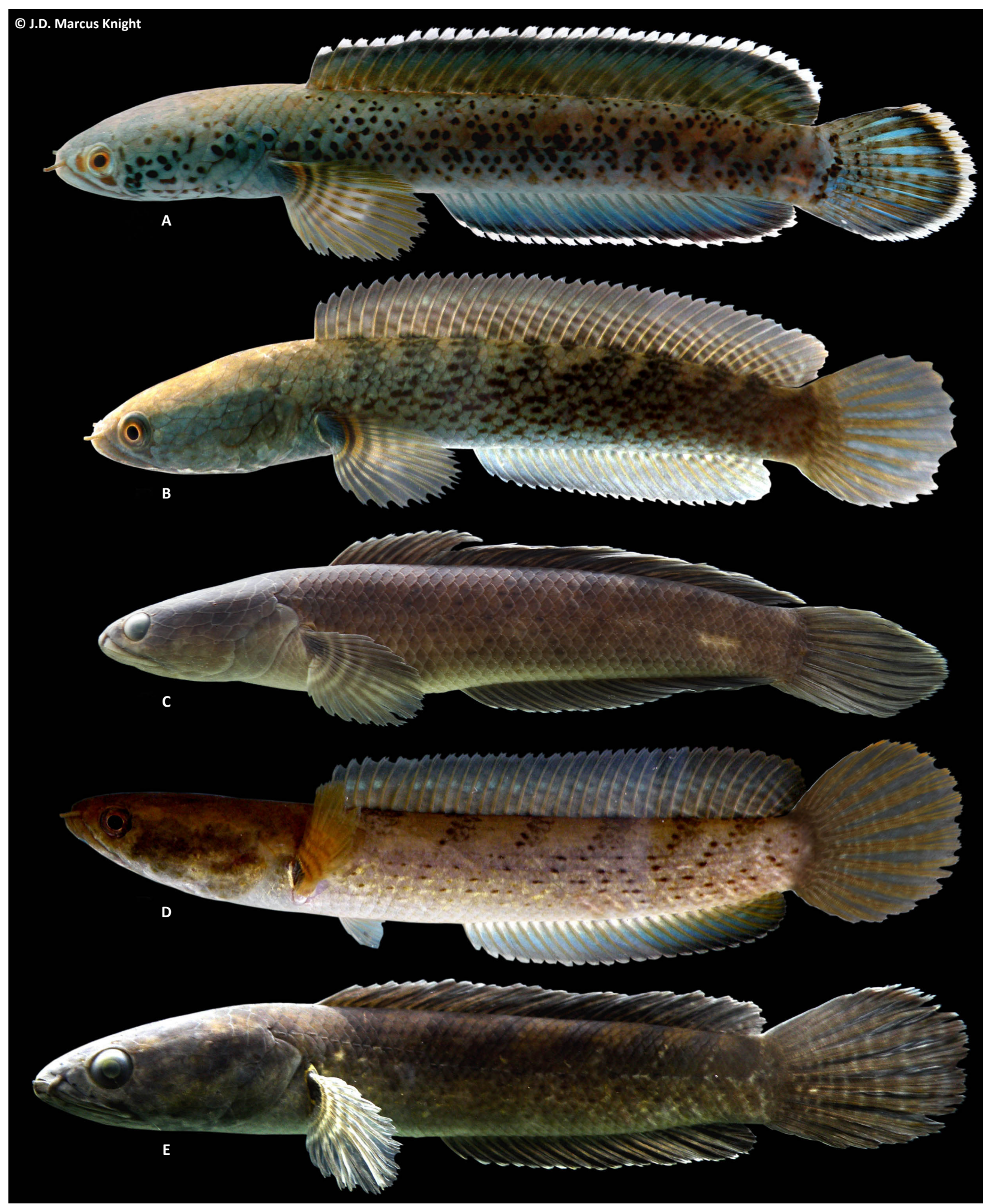

Image 2. Channa pardalis: A, paratype, ZSI/SRC F 8954, 139.3mm SL, showing live colouration, West Khasi Hills, Meghalaya. C. stewartii: MKC 100, Cachar, Assam, B, $109.2 \mathrm{~mm}$ SL, showing live colouration, C, $128.6 \mathrm{~mm} \mathrm{SL}$, showing colouration in preservative. C. melanostigma: MKC 012, Tinsukia, Assam, D, 118.1 mm SL showing live colouration, E, $122.9 \mathrm{~mm} \mathrm{SL}$, showing colouration in preservative. 


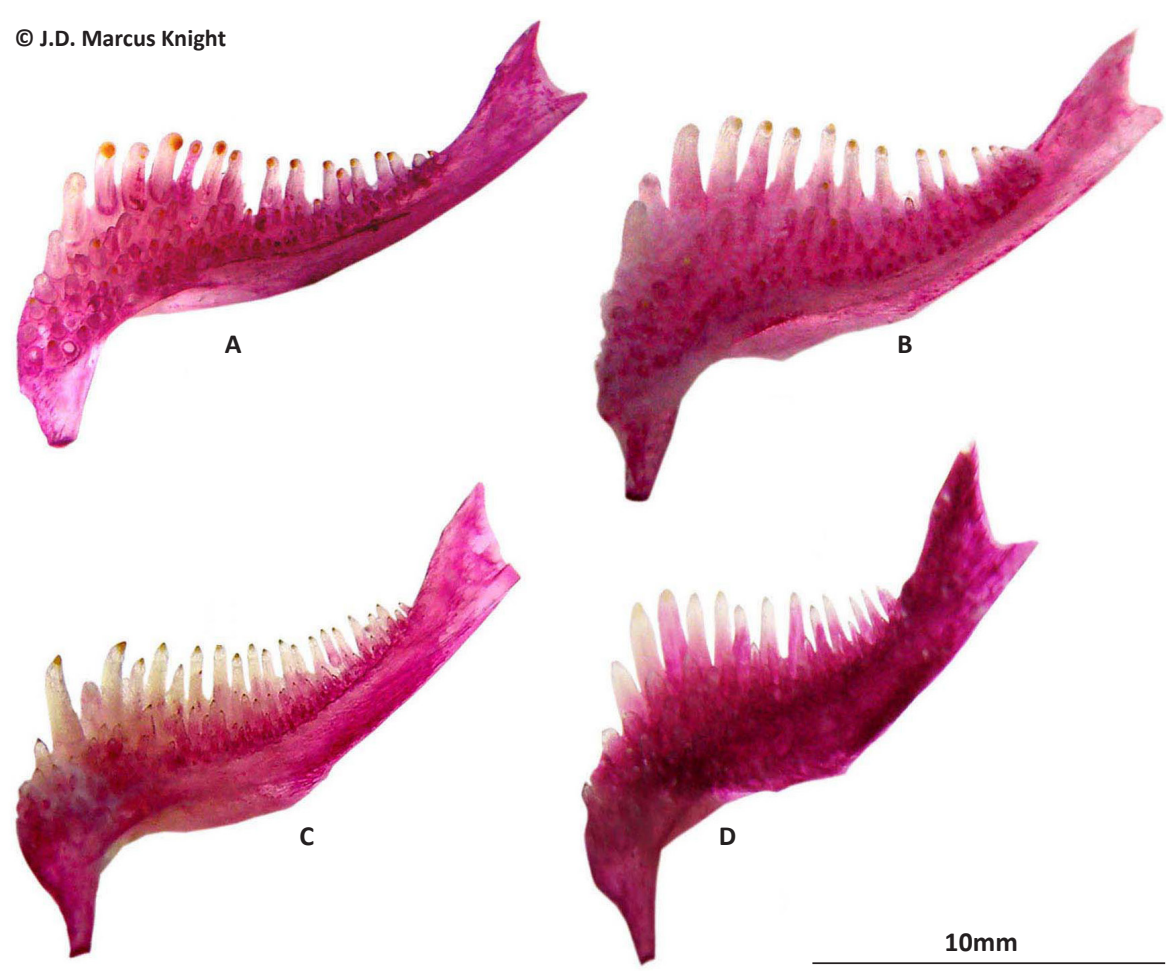

Image 3. Fifth ceratobranchial of Channa species: A - C. pardalis; B - C. stewartii; C - C. melanostigma; D - C. gachua.

\section{Note}

Channa pardalis sp. nov. is known in the ornamental fish trade as Channa sp. Meghalaya leopard.

\section{Discussion}

Britz (2008) proposed the 'Channa gachua species group' comprised of species with pectoral fins having a varying number of dark and light semicircular bands. In addition to $C$. orientalis, C. gachua, C. burmanica, $C$. bleheri and C. barca, Britz (2008) also included C. stewartii, C. aurantimaculata, C. ornatipinnis and C. pulchra to the 'C. gachua species group'. Two other recently described species, i.e., C. melanostigma and C. andrao also belong to the $C$. gachua species group. Channa pardalis sp. nov. in view of its pectoral fins having the characteristic semicircular dark and light bands, unquestionably belongs to this group.

Channa pardalis can be distinguished from C. orientalis, C. burmanica, $C$. bleheri and $C$. andrao by the presence of pelvic fins, and from $C$. ornatipinnis and C. pulchra by the pectoral fin having three or four alternating pale orange and grey semi-circular bands which fade towards the distal part of the fin (vs. four to five semicircular, narrow white bands alternating with brown or black bands). Channa pardalis can be further distinguished from both C. ornatipinnis and C. pulchra in having $6 \frac{1}{2}$ (vs. $7 \frac{1}{2}$ ) scales below lateral line at anal-fin origin, absence of black blotches on the anterior third of the dorsal fin and absence of parallel, oblique, linear white marks at anal fin base.

Though C. pardalis superficially resembles both C. stewartii and C. melanostigma, it can be easily distinguished from both by the presence of 15-20 welldefined black spots on the post-orbital region of the head and opercle, $6 \frac{1}{2}$ (vs. $7 \frac{1}{2}$ ) scales below lateral line at analfin origin, 45 (vs. 48 and 50-51) vertebrae respectively and a more slender fifth ceratobranchial (Image $3 \mathrm{~A}-\mathrm{C}$ ). Channa pardalis can be further distinguished from $C$. stewartii by having 36-37 (vs. 39-40) dorsal fin rays and $44-45+2$ (vs. $47-48+2$ ) lateral line scales, and from $C$. melanostigma by the absence (vs. presence) of 14-15 distinct zigzag cross bars on the caudal fin.

Channa pardalis can be distinguished from $C$. aurantimaculata and C. barca in having 36-37 (vs. 45-52) dorsal fin rays and $44-45+2$ (vs. $>50$ ) lateral line scales. Though C. pardalis is a part of the $C$. gachua species group it can be distinguished from $C$. gachua by the presence of numerous large black spots on the post-orbital region of the head, opercle and body, 45 (vs. 42) vertebrae and 36-37 (vs. 34-35) dorsal fin rays and a more slender fifth ceratobranchial (Image 3 A, D).

There are quite a few names buried in the synonymy of C. gachua. Of these Ophiocephalus aurantiacus Hamilton, 1822 (type locality: Goyalpara on the northeastern 
frontier of Bengal), Ophicephalus marginatus Cuvier, 1829 (type locality: Vizagapattam: see Kottelat 2000) and $O$. fuscus Cuvier, 1831 (type locality: Bengal) are from India. Channa pardalis can be distinguished from 0 . aurantiacus by having a bluish dorsum gradually becoming grey towards the abdomen, with numerous black spots along the flanks extending into the dorsal fin and caudal fin, vs. the whole body and fins being of the colour of orangepeel, with some irregular stains of a redder hue, especially on the sides of the head, and on the pectoral and tail fins. Channa pardalis can be distinguished from C. fuscus and $C$. marginatus (which were similar to $C$. gachua), in having more than 40 lateral line pored scales and by the presence of conspicuous black spots on the post-orbital region of the head, opercle and on the body.

Two other names, Ophicephalus montanus M'Clelland \& Griffith, 1842 (type locality: Afghanistan?) and Ophiocephalus kelaartii Günther, 1861 (type locality: Sri Lanka) are also currently synonyms of $C$. gachua (Kottelat 2013). Channa pardalis can be distinguished from 0 . montanus by having 36-37 (vs. 32) dorsal fin rays and 24-25 (vs. 17) anal fin rays. Channa pardalis can further be distinguished from 0 . kelaartii by having $44-45+2$ (vs. 38) lateral line scales and $24-25$ (vs. 22) anal fin rays. One other similar species is Ophiocephalus gachua var. basalis Günther, 1861 (type locality: East Indies) which is most probably C. gachua (Kottelat 2013) as Günther mentions that this species has a black ocellus edged with white on the hindmost part of the dorsal fin when young, typical of C. gachua. Channa pardalis can be distinguished from O. gachua var. basalis in having 24-25 (vs. 21-23) anal fin rays and $4 \frac{1}{2}$ (vs. 3) scales above lateral line. One other species, Ophicephalus nigricans Cuvier \& Valenciennes 1831 is currently a synonym of Channa barca. Channa pardalis can be distinguished from $O$. nigricans by having 36-37 (vs. 50) dorsal fin rays.

As mentioned by Britz (2008) the monophyly of the Channa gachua species group needs to be confirmed through phylogenetic studies. Further exploration of remote areas in northeastern India and adjoining areas may probably bring to light more snakehead species new to science or possibly find that some of the species currently synonymous with $C$. gachua to be valid species.

\section{COMPARATIVE MATERIAL}

Channa stewartii: MKC 100, 2, 109.2-128.6 mm SL, Cachar, near the border with Meghalaya, Assam, December 2010, A. Rao (128.6mm SL specimen was cleared and stained); MKC 192, 5, 78.1-121.2 mm SL, Jaigaon, Jalpaiguri district, West Bengal, March 2011, A. Rao (121.2mm SL specimen was cleared and stained).
Channa melanostigma: MKC 012, 4, 66.2-122.9 mm SL, Brahmaputra River, Tinsukia, Assam, November 2011, A. Rao (two specimen 120.2 and 122.9 mm SL were cleared and stained).

Channa gachua: MKC 191, 10, 56.6-98.2 mm SL, Ganrapota, North 24 Parganas, West Bengal, March 2011, A. Rao (two specimen 78.9 and $90.9 \mathrm{~mm} \mathrm{SL}$ were cleared and stained). MKC 182, 1, 52.1mm SL, Meghalaya, India, March 2011, A. Rao. MKC 430, 1, 49.7mm SL, Kaveripattanam, Tamil Nadu, India, July 2015, Nikhil Sood; MKC 431, 6, 56.3-97.9 mm SL, Visakhapatnam, India, July 2015, Pranay Kumar.

\section{REFERENCES}

Britz, R. (2008). Channa ornatipinnis and C. pulchra, two new species of dwarf snakeheads from Myanmar (Teleostei: Channidae). Ichthyological Exploration of Freshwaters 8(for 2007): 335-344.

Britz, R. (2013). Channa andrao, a new species of dwarf snakehead from West Bengal, India (Teleostei: Channidae). Zootaxa 3731(2): 287-294; http://dx.doi.org/10.11646/zootaxa.3731.2.9

Cuvier, G. (1829). Le regne animal distribue d'apres son organisation, pour servir de base a l'histoire naturelle des animaux et d'introduction a l'anatomie comparee. Deterville, Paris, 2: xv+406pp; http://dx.doi. org/10.1017/cbo9781139567084

Cuvier, G. \& A. Valenciennes (1831). Histoire Naturelle des Poissons. Tome septième. Levrault, Paris, xxix+531pp, pls. 170-208.

Geetakumari, K. \& W. Vishwanath (2011). Channa melanostigma, a new species of freshwater snakehead from north-east India (Teleostei: Channidae). Journal of the Bombay Natural History Society 107(for 2010): 231-235.

Günther, A. (1861). Catalogue of The Acanthopterygian Fishes in The Collection of The British Museum - Vol. 3. British Museum, London, xxv+586pp; http://dx.doi.org/10.5962/bhl.title.8320

Hamilton, F. (1822). An Account of the Fishes of River Ganges and its Branches. George Ramsay and Co., London, 405pp; http://dx.doi. org/10.5962/bhl.title.59540

Kottelat, M. (2000). Nomenclature and types of Ophicephalus marginatus and O. limbatus (Teleostei: Channidae). Journal of South Asian Natural History 5(1): 95-96.

Kottelat, M. (2013). The fishes of the inland waters of Southeast Asia: A catalogue and core bibliography of the fishes known to occur in freshwaters, mangroves and estuaries. The Raffles Bulletin of Zoology, 27 (Supplement): 1-663.

Liem, K.F. (1980). Air ventilation in advanced teleosts: biomechanical and evolutionary aspects, pp. 57-91. In: Ali, M.A. (ed.). Environmental physiology of fishes. Plenum Press, New York; http://dx.doi. org/10.1007/978-1-4899-3659-2_4

M'Clelland, J. (1842). On the freshwater fishes collected by William Griffith during his travels from 1835 to 1842. Cal J Nat Hist, Miscellaneous Arts and Sciences in India 2(8): 560-589, pls. 6, 15, 18, 21.

Musikasinthorn, P. (1998). Channa panaw, a new channid fish from the Irrawaddy and Sittang basins, Myanmar. Ichthyological Research 45: 355-362; http://dx.doi.org/10.1007/bf02725188

Musikasinthorn, P. (2000). Channa aurantimaculata, a new channid fish from Assam (Brahmaputra River basin), India, with designation of a neotype for C. amphibeus (McClelland, 1845). Ichthyological Research 47: 27-37. http://dx.doi.org/10.1007/bf02674310

Playfair, R.L. (1867). On the fishes of Cachar. Proceedings of the Zoological Society of London, (pt 1): 14-17, PI. 3

Taylor, W.R. \& G.C. van Dyke (1985). Revised procedures for staining and clearing small fishes and other vertebrates for bone and cartilage study. Cybium 9: 107-119. 